\title{
Taxa respiratória de frutas de clima temperado
}

\author{
Cristiano André Steffens ${ }^{(1)}$, Auri Brackmann ${ }^{(2)}$, Josuel Alfredo Vilela Pinto(2) e Ana Cristina Eisermann ${ }^{(2)}$
}

\begin{abstract}
(1)Universidade do Estado de Santa Catarina, Centro de Ciências Agroveterinárias, Av. Luiz de Camões, oo 2090, Bairro Conta Dinheiro, CEP 88520-000 Lages, SC. E-mail: steffens@cav.udesc.br (2)Universidade Federal de Santa Maria, Centro de Ciências Rurais, Av. Roraima, no 1000, Cidade Universitária, Bairro Camobi, CEP 97105-900 Santa Maria, RS. E-mail: brackman@ccr.ufsm.br, josuelpinto@bol.com.br, anna_eisermann@yahoo.com.br
\end{abstract}

\begin{abstract}
Resumo - O objetivo deste trabalho foi avaliar o efeito do estádio de maturação, da temperatura e da modificação da atmosfera, durante o armazenamento, sobre a taxa respiratória de cultivares de maçã, caqui, quiuí e pêssego. A relação entre taxa respiratória e o potencial de armazenamento foi avaliada. Os tratamentos utilizados foram dois estádios de maturação (verde-maduro e maduro), três temperaturas $\left(0,10\right.$ e $\left.20^{\circ} \mathrm{C}\right)$ e duas condições de armazenamento (armazenamento refrigerado e atmosfera modificada). As cultivares avaliadas foram Gala e Fuji, em maçã, Fuyu, Giombo, Rama Forte, Taubaté e Coração de Boi, em caqui, Bruno e Hayward, em quiuí, Eldorado, Jubileu e Maciel, em pêssego. Maçãs 'Gala', armazenadas a $0^{\circ} \mathrm{C}$, e 'Fuji', a 0 e $10^{\circ} \mathrm{C}$, não apresentaram pico respiratório característico de frutos climatéricos. A temperatura exerceu forte efeito sobre a respiração; o incremento na taxa respiratória, pelo aumento da temperatura, variou conforme a espécie e a faixa de temperatura analisada. A modificação da atmosfera, em média, reduziu a taxa respiratória em $14,3 \%$, nas frutas armazenadas a $0^{\circ} \mathrm{C}$. A taxa respiratória é influenciada pelos fatores cultivar, temperatura de armazenamento e modificação da atmosfera.

Termos para indexação: armazenamento, pós-colheita, atmosfera modificada.
\end{abstract}

\section{Respiratory rate of fruits of temperate climate}

\begin{abstract}
The objective of this work was to evaluate the effect of ripening stages, temperature and modification of atmosphere during storage on the respiratory rate of some cultivars of apple, persimmon, kiwi and peaches, as well as the relation between respiration rate and storage potential. Evaluated treatments were two ripening stages (mature-green and tree-ripe), three temperatures $\left(0,10\right.$ and $\left.20^{\circ} \mathrm{C}\right)$ and two storage conditions (cold storage and modified atmosphere). The cultivars Gala and Fuji, of apple, Fuyu, Giombo, Rama Forte, Taubaté and Coração de Boi, of persimmon, Bruno and Hayward, of kiwi, Eldorado, Jubileu and Maciel, of peaches were evaluated. 'Gala' apples, stored at $0^{\circ} \mathrm{C}$, and 'Fuji' apples, at 0 and $10^{\circ} \mathrm{C}$, did not show a climateric respiratory rise. Temperature had a strong effect on the respiration; the increment in respiratory rate, by increasing of temperature, varied according to species and temperature. The modification of atmosphere, on average, reduced the respiratory rate in $14.3 \%$, at $0^{\circ} \mathrm{C}$. The respiratory rate is influenced by cultivar, temperature of storage and atmosphere modification.
\end{abstract}

Index terms: storage, postharvest, modified atmosphere.

\section{Introdução}

O armazenamento de frutas em atmosfera modificada vem sendo utilizado por pequenos e médios produtores como alternativa na conservação desses produtos perecíveis, uma vez que exige investimento mais baixo e menor nível de tecnologia que a atmosfera controlada (Brackmann et al., 2004). A atmosfera modificada, quando utilizada corretamente, torna-se eficiente em retardar o metabolismo e manter a qualidade do produto por períodos prolongados de armazenamento (Chen et al., 2000).
Segundo Brackmann \& Chitarra (1998), o uso correto da atmosfera modificada ocorre quando a modificação da atmosfera atinge níveis de $\mathrm{O}_{2}$ e $\mathrm{CO}_{2}$ que retardam a atividade respiratória, porém não causam danos ao tecido vegetal.

Atualmente, no Brasil, essa técnica de conservação está sendo utilizada comercialmente para o transporte e armazenamento de um número limitado de frutas, as quais suportam baixos níveis de $\mathrm{O}_{2}$ ou altos de $\mathrm{CO}_{2}$, como o morango e o caqui. Isto se deve ao alto risco de redução dos níveis de $\mathrm{O}_{2}$ ou aumento do $\mathrm{CO}_{2}$ dentro da 
embalagem, uma vez que a alteração nas pressões parciais dos gases se estabelece pelo balanço entre a taxa respiratória do produto embalado e a permeabilidade da embalagem aos gases (Peppelenbos et al., 1996; Fonseca et al., 2002). Redução excessiva de $\mathrm{O}_{2}$ ou aumento do $\mathrm{CO}_{2}$ pode desencadear o metabolismo fermentativo e o desenvolvimento de sabor e aroma alcoólico e de deterioração da polpa (Song et al., 2002). Em atmosfera modificada isto é passível de ocorrer, pois não se conhece a taxa respiratória dos frutos e a permeabilidade dos filmes poliméricos nas condições de armazenamento, não sendo possível prever os níveis de gases da atmosfera no interior da embalagem depois de determinado tempo de armazenamento.

De acordo com Mahajan \& Goswani (2001), a respiração é o principal fator a ser considerado no planejamento e no dimensionamento do sistema de armazenamento em atmosfera modificada ou controlada. Fonseca et al. (2002) e Petracek et al. (2002) também consideram a respiração como fator determinante da magnitude da modificação da atmosfera. Song et al. (2002) afirmam que o conhecimento da taxa respiratória dos frutos permite prever a composição dos gases dentro da embalagem durante o armazenamento. Além disso, Manolopoulou \& Papadopoulou (1998) e Chitarra (1998) afirmam que a intensidade da taxa respiratória está relacionada com a capacidade de armazenamento do produto, e que, quanto maior a taxa respiratória, menor é o tempo de armazenamento.

O objetivo deste trabalho foi avaliar a respiração de frutas de clima temperado com destaque econômico no Brasil, de acordo com o estádio de maturação, a cultivar, temperatura e a modificação da atmosfera de armazenamento, bem como avaliar a relação entre a taxa respiratória dos frutos e seu potencial de armazenamento.

\section{Material e Métodos}

Foram conduzidos três experimentos, em 2004, com maçãs, caquis, quiuís e pêssegos. No experimento 1 , os tratamentos originaram-se da combinação entre os fatores estádio de maturação (verde-maduro e maduro) e cultivares - Gala e Fuji, para maçã; Fuyu, Rama Forte, Taubaté, Giombo e Coração de Boi, para caqui; Jubileu, Maciel e
Eldorado, para pêssego. O efeito desses dois fatores sobre a taxa respiratória foi avaliado. Também avaliou-se, nesse experimento, as cultivares de quiuí Bruno e Hayward, porém somente em um estádio de maturação.

Os frutos dos estádios de maturação verde-maduro e maduro apresentavam os seguintes atributos de qualidade: maçã 'Gala' apresentou ângulo hue de 103,8 e 84,7, firmeza de polpa de 73,2 e 71,1 N, e índice de iodo-amido de 7,2 e 8, nos estádios de maturação verdemaduro e maduro, respectivamente; a maçã 'Fuji' apresentou ângulo hue de 98,5 e 85,4, firmeza de polpa de 70,3 e 68,6 $\mathrm{N}$ e índice de iodo-amido de 7 e 8,1, respectivamente. O pêssego 'Maciel' registrou ângulo hue de 103,5 e 92,4, firmeza de polpa de 53,3 e 51,7 N, acidez titulável de 15,7 e $15,1 \mathrm{cmol} \mathrm{L}^{-1}$ e sólidos solúveis totais de 11,1 e $11,9^{\circ}$ Brix nos estádios de maturação verde-maduro e maduro, respectivamente. O pêssego 'Jubileu' registrou ângulo hue de 105,7 e 94,1, firmeza de polpa de 53,7 e 50,2 N, acidez titulável de 12,8 e $12,1 \mathrm{cmol} \mathrm{L}^{-1}$ e sólidos solúveis totais de 11,1 e 11,9³rix nos estádios de maturação verde-maduro e maduro, respectivamente. O pêssego 'Eldorado' apresentou firmeza de polpa de 58,2 e 56,3 N, acidez titulável de 11,1 e $10,2 \mathrm{cmol} \mathrm{L}^{-1}$ e sólidos solúveis totais de $11,8 \mathrm{e}$ $12,4^{\circ}$ Brix para os estádios de maturação verde-maduro e maduro, respectivamente. Os caquis apresentavam epiderme verde-amarela, no estádio verde-maduro, e amarelo-avermelhada, no estádio de maturação maduro.

No experimento 2 , avaliou-se o efeito das temperaturas 0,10 e $20^{\circ} \mathrm{C}$ sobre a respiração das cultivares Gala e Fuji, em maçã, Hayward e Bruno, em quiuí, Fuyu e Rama Forte, em caqui, e Jubileu, em pêssego.

No experimento 3, os tratamentos originaram-se da combinação entre os fatores espécie de fruta (caqui, maçã, quiuí e pêssego) e condição de armazenamento (armazenamento refrigerado e atmosfera modificada).

Os três experimentos seguiram o delineamento inteiramente casualizado, e cada tratamento foi constituído por três repetições. Os pêssegos foram provenientes de pomares comerciais localizados no Município de Canguçu, as maçãs de pomares comerciais de Vacaria, o caqui 'Fuyu' e os quiuís de pomares comerciais de Farroupilha e os caquis 'Rama Forte', 'Giombo', 'Taubaté' e 'Coração de Boi' foram provenientes do pomar didático da Universidade Federal de Santa Maria, em Santa 
Maria. Todos os municípios estão localizados no Estado do Rio Grande do Sul.

Nos experimentos 1 e 2, os frutos foram acondicionados em recipientes de vidro com capacidade de $5.000 \mathrm{~mL}$, e, a fim de determinar a respiração, estes vidros foram hermeticamente fechados por 2 horas a cada 3 dias, 12 horas a cada 5 dias e 48 horas a cada 7 dias, nas temperaturas de 20,10 e $0^{\circ} \mathrm{C}$, respectivamente. Nestes experimentos, a unidade experimental foi composta por $1.000 \mathrm{~g}$ de frutos.

No experimento 3 , os frutos foram acondicionados em minicâmaras experimentais com capacidade de $60 \mathrm{~L}$, sendo a unidade experimental composta por uma massa de $15.000 \mathrm{~g}$ de frutos. Na condição de armazenamento refrigerado, as minicâmaras experimentais foram fechadas por 72 horas para ocorrer o acúmulo de $\mathrm{CO}_{2}$ necessário para a quantificação da respiração. $\mathrm{Na}$ condição de armazenamento em atmosfera modificada, as pressões parciais dos gases foram obtidas mediante a diluição do $\mathrm{O}_{2}$ no ambiente de armazenamento com injeção de $\mathrm{N}_{2}$, proveniente de um gerador de nitrogênio, que utiliza o princípio "Pressure Swing Adsorption" (PSA), e posterior injeção de $\mathrm{CO}_{2}$, provenientes de cilindros de alta pressão, até atingir o nível preestabelecido no tratamento. As condições de armazenamento foram $5 \mathrm{kPa}$ de $\mathrm{O}_{2}+5 \mathrm{kPa}$ de $\mathrm{CO}_{2}$, para maçã 'Gala', quiuí 'Bruno' e pêssego 'Jubileu', e $10 \mathrm{kPa}$ de $\mathrm{O}_{2}+10 \mathrm{kPa}$ de $\mathrm{CO}_{2}$, para o caqui 'Fuyu'. Essas pressões parciais de gases foram utilizadas por serem condições que poderiam ser obtidas durante o armazenamento em atmosfera modificada, sem apresentar risco de desenvolver distúrbios fisiológicos decorrentes de metabolismo fermentativo.

A manutenção das pressões parciais desejadas dos gases, nas diferentes condições de armazenamento, foi realizada diariamente. As avaliações das pressões parciais dos gases foram feitas por meio de analisadores eletrônicos de $\mathrm{CO}_{2}$ e $\mathrm{O}_{2}$, marca Agri-Datalog, e com posterior correção, até atingir os níveis preestabelecidos. O oxigênio consumido pela respiração foi reposto por meio da injeção de ar atmosférico nas minicâmaras e o $\mathrm{CO}_{2}$ em excesso foi absorvido por uma solução de hidróxido de potássio ( $40 \%$ p/v), através da qual foi circulado o ar do ambiente de armazenamento. Quando foi realizada a determinação da respiração dos frutos nessa condição, a correção da atmosfera foi realizada somente 48 horas após o início do período de determinação da respiração.
A taxa respiratória foi determinada pela produção de $\mathrm{CO}_{2}$. O gás do espaço livre do recipiente de vidro ou da minicâmara, utilizado no acondicionamento das amostras, foi circulado por meio de analisadores eletrônicos de $\mathrm{O}_{2}$ e $\mathrm{CO}_{2}$, marca Agri-Datalog. Com base na concentração de $\mathrm{CO}_{2}$, no volume do espaço livre, na massa de frutos e no tempo de fechamento, foi calculada a respiração, sendo os valores expressos em mililitro de $\mathrm{CO}_{2} \mathrm{~kg}^{-1} \mathrm{~h}^{-1}$. Também foi calculado, no experimento 2 , o quociente da temperatura de respiração $\left(\mathrm{Q}_{10}\right)$, que é a relação entre a taxa de uma reação específica numa dada temperatura versus a taxa de reação na temperatura acrescida de $10^{\circ} \mathrm{C}$ (Chitarra, 1998). Para este cálculo, utilizou-se a equação $\mathrm{Q}_{10}=\left(\mathrm{R}_{2} / \mathrm{R}_{1}\right)^{10 /\left(\mathrm{T}_{2}-\mathrm{T}_{1}\right)}$, em que $\mathrm{R}_{2}$ é a taxa respiratória na temperatura $T_{2}$ e $\mathrm{R}_{1}$ é a taxa respiratória na temperatura $T_{1}$.

A análise de variância seguiu o modelo do delineamento inteiramente casualizado. Nos experimentos $1 \mathrm{e}$ 3 , as médias foram comparadas pelo teste de Duncan, a $5 \%$ de probabilidade. No experimento 2, as médias foram submetidas a análise de regressão linear simples.

\section{Resultados e Discussão}

Observou-se que, a $0^{\circ} \mathrm{C}$, não foi possível detectar o pico climatérico na respiração das cultivares de maçã Gala e Fuji. De acordo com Chitarra (1998), quando o fruto fica exposto à temperatura próxima ao limite fisiológico de tolerância pela cultivar, o pico climatérico pode ser suprimido. Esta afirmação sustenta os resultados obtidos com as cultivares Gala e Fuji a $0^{\circ} \mathrm{C}$. Já a 10 e $20^{\circ} \mathrm{C}$, somente na cultivar Fuji não foi possível observar o pico respiratório (Figuras 1 e 2). Saquet \& Streif (2000) também não observaram pico respiratório na cultivar Fuji. De acordo com Chitarra (1998), o aumento na taxa respiratória é um evento secundário, estimulado pelo aumento na taxa de produção de etileno durante o amadurecimento dos frutos. Diante disso, o comportamento observado na cultivar Fuji pode ser considerado previsível, pois essa cultivar apresenta pouca resposta ou até mesmo nenhuma resposta ao etileno, conforme Brackmann et al. (2001).

A medida em que a temperatura aumentou, o pico respiratório foi antecipado (Figuras 1 e 2). Esse resultado está de acordo com Chitarra (1998), que afirma que temperaturas mais baixas retardam o pico climatérico. 
Com relação ao estádio de maturação, verificou-se que o pico respiratório foi antecipado no caqui 'Fuyu' colhido no estádio maduro, nas três temperaturas estudadas
(Figura 2 D, E e F). Este resultado era esperado em todas as cultivares e espécies avaliadas, no entanto, a taxa respiratória máxima pode ocorrer desde o estádio
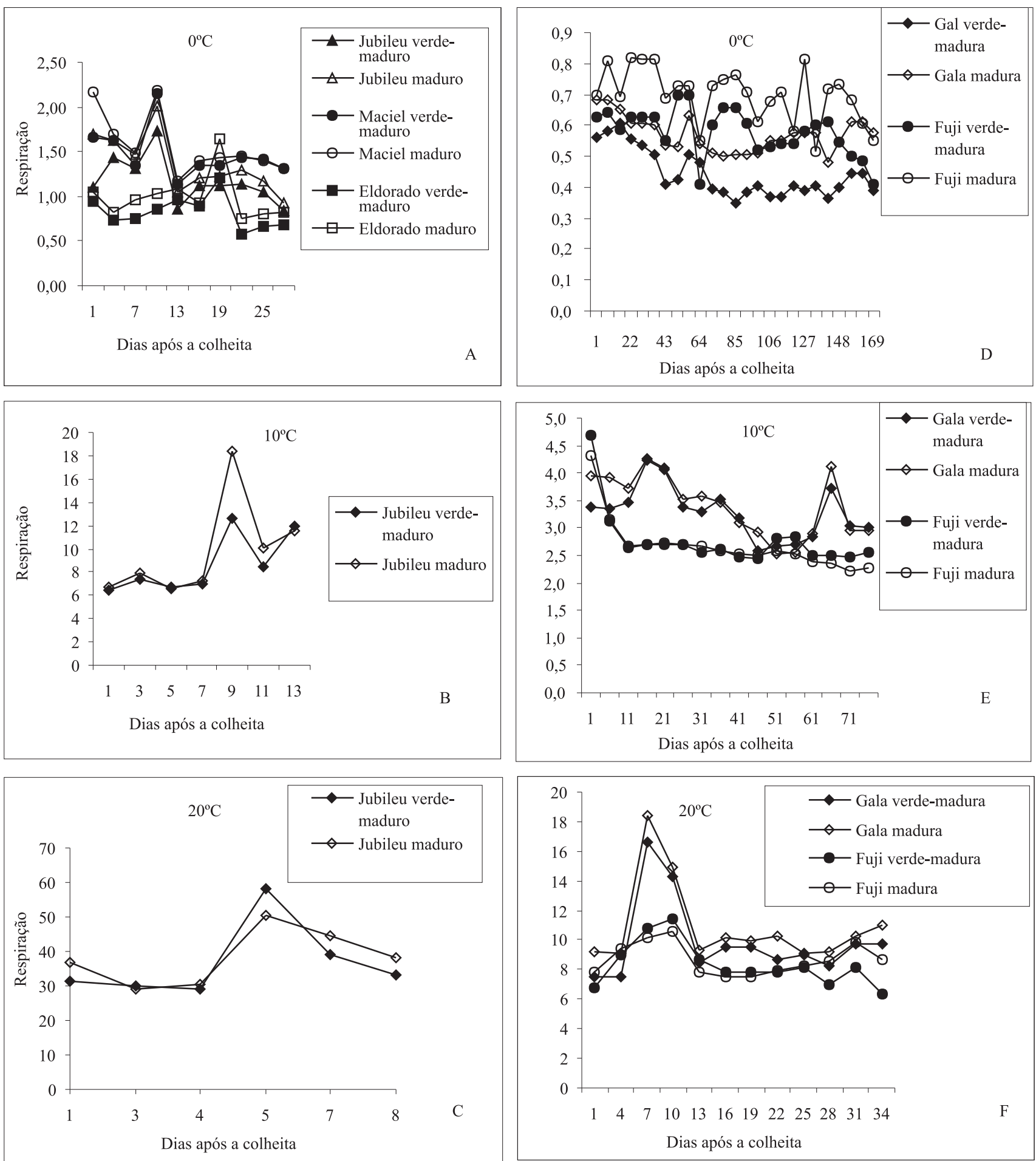

Figura 1. Respiração $\left(\mathrm{mL} \mathrm{CO}_{2} \mathrm{~kg}^{-1} \mathrm{~h}^{-1}\right)$ de frutos de cultivares de pêssego (A, B, e C) e maçã ( $\left.\mathrm{D}, \mathrm{Ee} \mathrm{F}\right)$ a 0,10 e $20^{\circ} \mathrm{C}$. Experimento 1. 
de maturação maduro até o supermaduro (Chitarra, 1998).
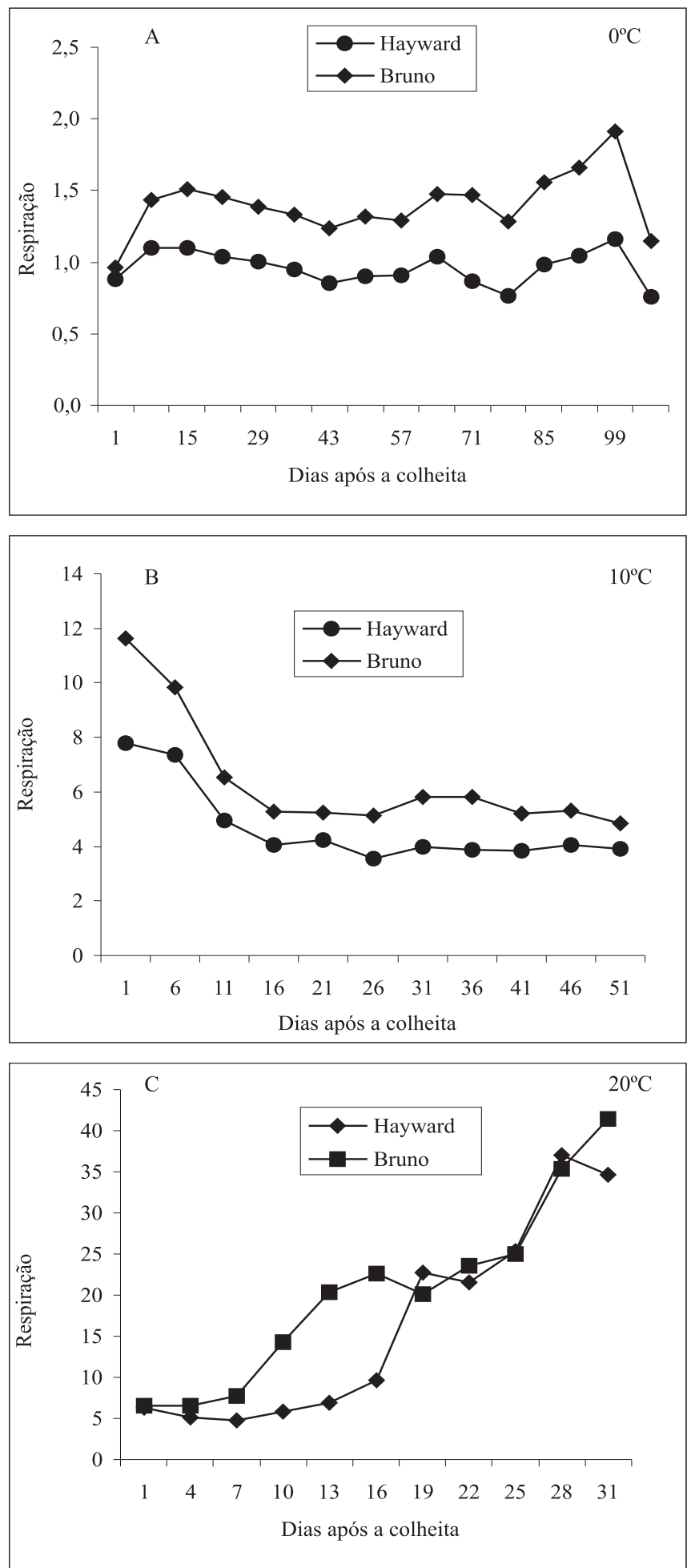

Os frutos colhidos no estádio maduro apresentaram maior taxa respiratória média em maçã e no caqui
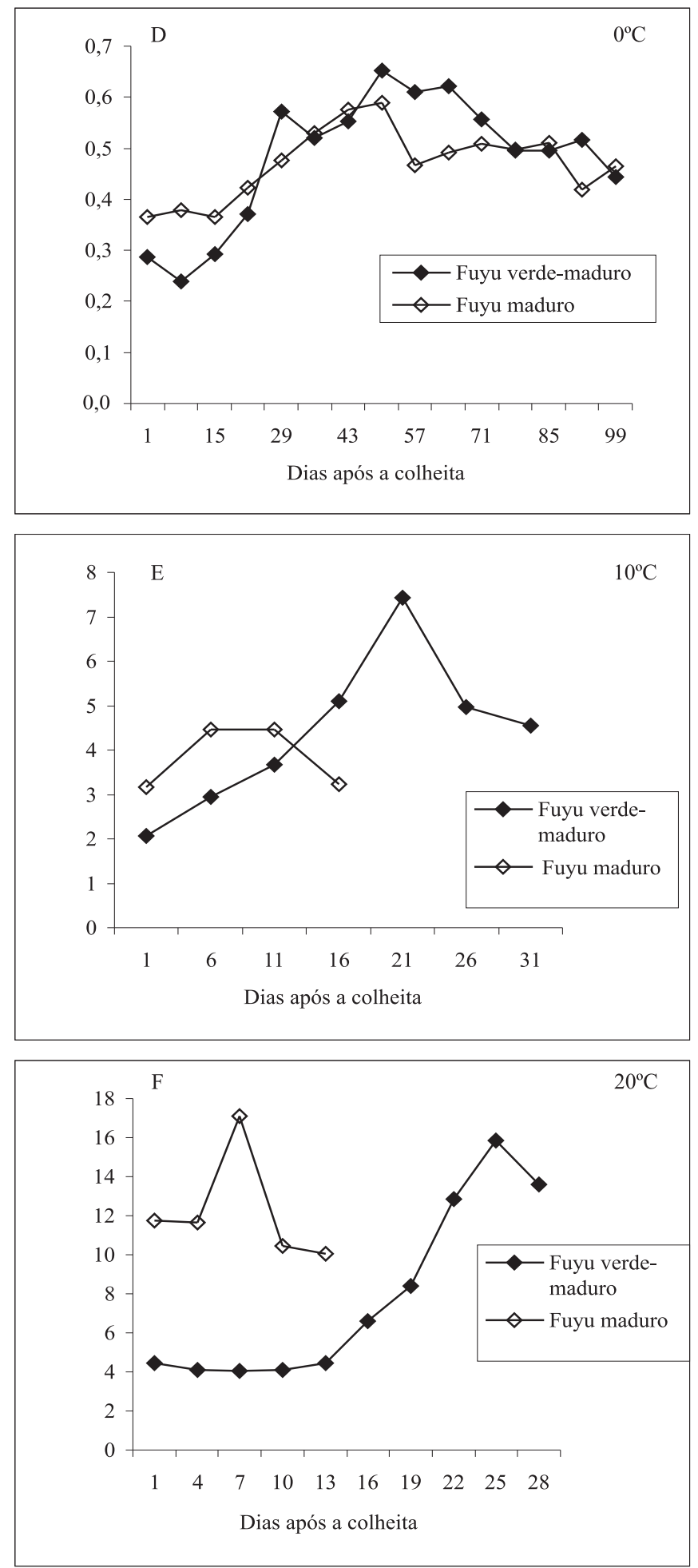

Figura 2. Respiração $\left(\mathrm{mL} \mathrm{CO}_{2} \mathrm{~kg}^{-1} \mathrm{~h}^{-1}\right)$ de frutos de cultivares de quiuí (A, B e C) e de caqui (D, E e F) a 0,10 e $20^{\circ} \mathrm{C}$. Experimento 1. 
'Giombo' mantidos a $0^{\circ} \mathrm{C}$, porém menor nos caquis 'Rama Forte' e 'Fuyu' armazenados a $10^{\circ} \mathrm{C}$. Fonseca et al. (2002) citam que o estádio de maturação normalmente influencia a atividade respiratória. No entanto, pode ser possível observar atividade respiratória semelhante entre frutos de diferentes estádios de maturação (Steffens, 2003). Cultivares com taxa respiratória maior foram a Fuji a $0^{\circ} \mathrm{C}$ e a Gala a 10 e $20^{\circ} \mathrm{C}$, em maçã, Maciel, em pêssego, Rama Forte, em caqui, e Bruno, em quiuí (Tabelas 1 e 2). As cultivares mais precoces apresentaram taxa respiratória maior quando comparadas com cultivares mais tardias (Tabelas $1 \mathrm{e}$ 2). Este resultado está de acordo com Manolopoulou \& Papadopoulou (1998) que observaram, em quiuí, que cultivares precoces apresentam maior atividade respiratória do que cultivares mais tardias. Brackmann \& Streif (1994) e Saquet \& Streif (2002) também verificaram, em maçãs produzidas na Alemanha, que cultivares tardias, como a Fuji, apresentam taxa respiratória menor que a Gala, de maturação mais precoce. No entanto, neste trabalho, na temperatura de $0^{\circ} \mathrm{C}$, a cultivar Fuji, tardia, apresentou maior atividade

Tabela 1. Taxa respiratória média $\left(\mathrm{mL}\right.$ de $\left.\mathrm{CO}_{2} \mathrm{~kg}^{-1} \mathrm{~h}^{-1}\right)$ de frutos de cultivares de maçã, caqui e pêssego, em função do estádio de maturação, em três temperaturas de armazenamento. Experimento $1^{(1)}$.

\begin{tabular}{|c|c|c|c|c|}
\hline \multirow{2}{*}{$\begin{array}{c}\text { Temperatura } \\
\left({ }^{\circ} \mathrm{C}\right)\end{array}$} & \multirow[t]{2}{*}{ Cultivar } & \multicolumn{2}{|c|}{ Estádio de maturação } & \multirow[t]{2}{*}{ Média } \\
\hline & & M1 & M2 & \\
\hline \multirow{5}{*}{0} & & & Maçã & \\
\hline & Gala & 0,47 & 0,57 & $0,52 b$ \\
\hline & Fuji & 0,58 & 0,67 & $0,63 \mathrm{a}$ \\
\hline & Média & $0,53 \mathrm{~B}$ & $0,62 \mathrm{~A}$ & \\
\hline & Coeficiente de variação (\%) & & & 9,12 \\
\hline \multirow[t]{4}{*}{10} & Gala & 3,34 & 3,48 & $3,41 \mathrm{a}$ \\
\hline & Fuji & 2,77 & 2,68 & $2,73 b$ \\
\hline & Média & $3,06 \mathrm{~A}$ & $3,08 \mathrm{~A}$ & \\
\hline & Coeficiente de variação (\%) & & & 6,63 \\
\hline \multirow[t]{4}{*}{20} & Gala & 10,03 & 11,07 & $10,55 \mathrm{a}$ \\
\hline & Fuji & 8,32 & 8,68 & $8,50 \mathrm{~b}$ \\
\hline & Média & $9,17 \mathrm{~A}$ & $9,88 \mathrm{~A}$ & \\
\hline & Coeficiente de variação (\%) & & & 6,13 \\
\hline \multirow{8}{*}{0} & & & Caqui & \\
\hline & Fuyu & 0,49Ad & $0,47 \mathrm{Ac}$ & 0,48 \\
\hline & Giombo & $0,61 \mathrm{Bc}$ & $0,69 \mathrm{Aa}$ & 0,65 \\
\hline & Taubaté & $0,46 \mathrm{Ad}$ & $0,51 \mathrm{Ac}$ & 0,49 \\
\hline & Rama Forte & $0,78 \mathrm{Aa}$ & $0,73 \mathrm{Aa}$ & 0,76 \\
\hline & Coração de Boi & $0,69 \mathrm{Ab}$ & $0,63 \mathrm{Ab}$ & 0,65 \\
\hline & Média & 0,60 & 0,61 & \\
\hline & Coeficiente de variação (\%) & & & 5,62 \\
\hline \multirow[t]{4}{*}{10} & Fuyu & 4,39 & 3,92 & $4,16 b$ \\
\hline & Rama Forte & 6,84 & 5,92 & $6,38 \mathrm{a}$ \\
\hline & Média & $5,62 \mathrm{~A}$ & $4,92 \mathrm{~B}$ & \\
\hline & Coeficiente de variação (\%) & & & 8,68 \\
\hline \multirow[t]{7}{*}{20} & Fuyu & 7,64 & 11,80 & $9,73 \mathrm{c}$ \\
\hline & Giombo & 14,36 & 14,69 & $14,53 b$ \\
\hline & Taubaté & 14,54 & 13,73 & $14,14 b$ \\
\hline & Rama Forte & 22,00 & 23,56 & $22,78 \mathrm{a}$ \\
\hline & Coração de Boi & 10,92 & 11,50 & $11,21 \mathrm{c}$ \\
\hline & Média & $13,90 \mathrm{~A}$ & $15,06 \mathrm{~A}$ & \\
\hline & Coeficiente de variação $(\%)$ & & & 13,64 \\
\hline \multirow{6}{*}{0} & & & Pêssego & \\
\hline & Maciel & 1,52 & 1,55 & $1,54 \mathrm{a}$ \\
\hline & Jubileu & 1,16 & 1,33 & $1,24 b$ \\
\hline & Eldorado & 0,81 & 0,98 & $0,89 \mathrm{c}$ \\
\hline & Média & $1,16 \mathrm{~A}$ & $1,29 \mathrm{~A}$ & \\
\hline & Coeficiente de variação (\%) & & & 5,64 \\
\hline
\end{tabular}

\footnotetext{
${ }^{(1)}$ Médias seguidas por letras distintas, maiúsculas na linha e minúsculas na coluna, diferem entre si pelo teste de Duncan, a $5 \%$ de probabilidade.
} 
respiratória que a maçã 'Gala' (Tabela 1). O fato de que, no Brasil, câmaras com maçã 'Fuji' necessitam maior reposição de oxigênio do que com maçã 'Gala', durante

Tabela 2. Taxa respiratória média $\left(\mathrm{mL}\right.$ de $\left.\mathrm{CO}_{2} \mathrm{~kg}^{-1} \mathrm{~h}^{-1}\right)$ de quiuís de acordo com a cultivar, em três temperaturas de armazenamento. Experimento $1^{(1)}$.

\begin{tabular}{lccc}
\hline Cultivar & \multicolumn{3}{c}{ Temperatura $\left({ }^{\circ} \mathrm{C}\right)$} \\
\cline { 2 - 4 } & 0 & 10 & 20 \\
\hline Hayward & $0,97 \mathrm{~b}$ & $4,69 \mathrm{~b}$ & $16,92 \mathrm{~b}$ \\
Bruno & $1,43 \mathrm{a}$ & $6,43 \mathrm{a}$ & $20,63 \mathrm{a}$ \\
\hline Média & 1,20 & 5,56 & 18,78 \\
Coeficiente de variação (\%) & 6,81 & 4,33 & 2,76 \\
\hline
\end{tabular}

${ }^{(1)}$ Médias seguidas por letras distintas diferem entre si pelo teste de Duncan, a $5 \%$ de probabilidade.
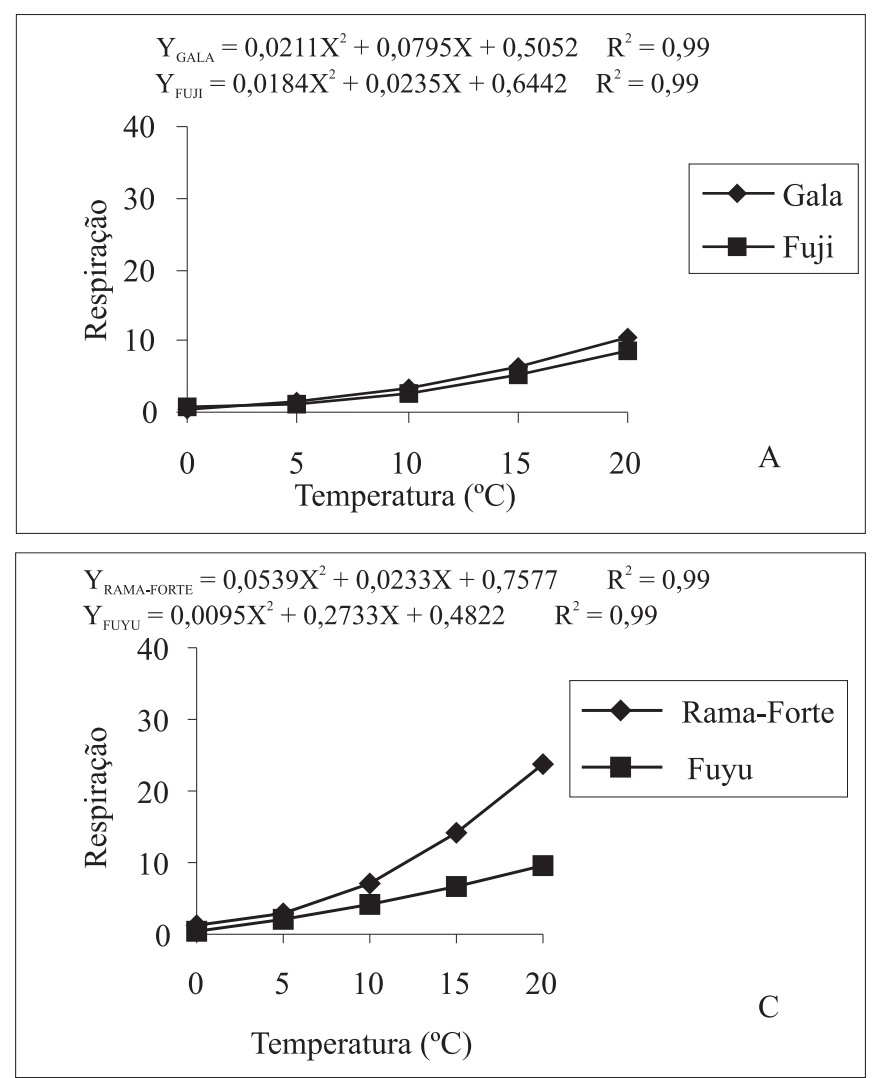

o armazenamento em atmosfera controlada na temperatura em torno de $0^{\circ} \mathrm{C}$, evidencia que, em baixas temperaturas, a cultivar Fuji apresenta atividade respiratória maior do que a Gala.

Com relação ao efeito da temperatura, observou-se, em todas as cultivares e espécies, que a redução da temperatura exerceu forte influência sobre a diminuição da taxa respiratória (Figura 3 e Tabela 3). Este resultado está de acordo com Chitarra (1998) e Fonseca et al. (2002) que afirmam que a redução da temperatura diminui a atividade respiratória dos frutos. No entanto, esses autores também citam que o aumento em $10^{\circ} \mathrm{C}$
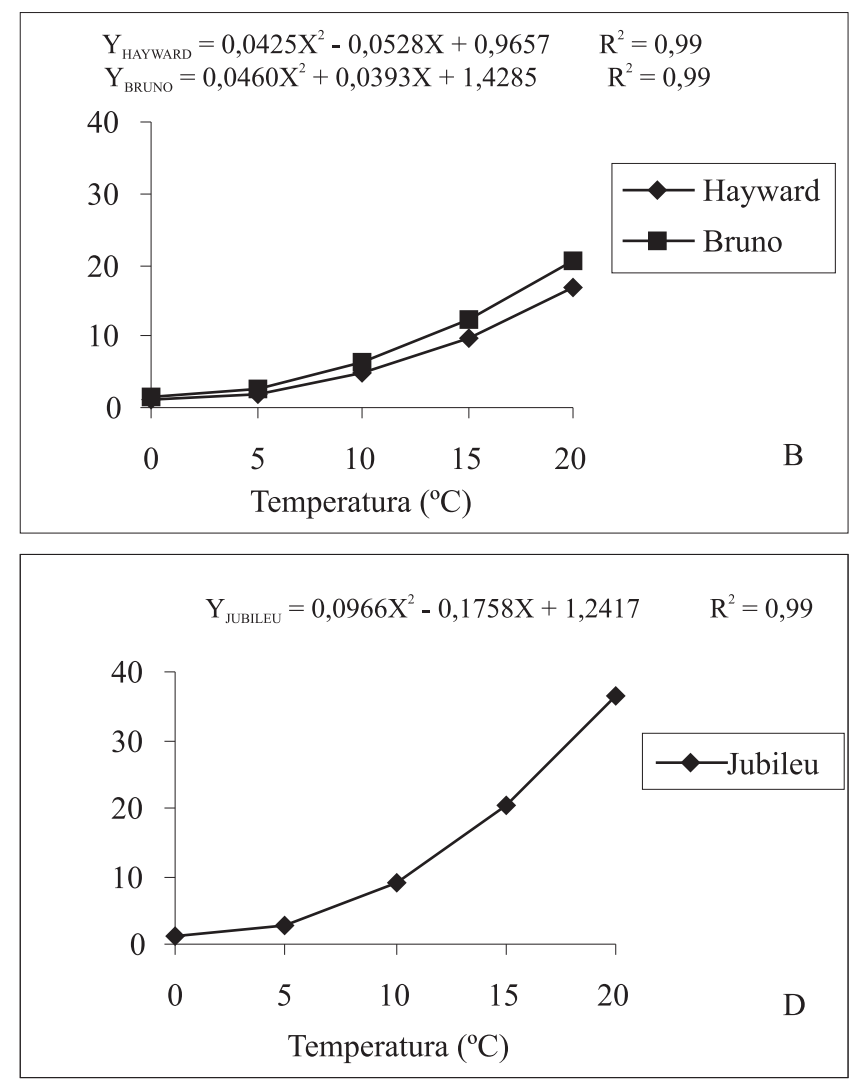

Figura 3. Respiração $\left(\mathrm{mL} \mathrm{CO}_{2} \mathrm{~kg}^{-1} \mathrm{~h}^{-1}\right)$ de frutos de cultivares de maçã (A), quiuí (B), caqui (C) e pêssego (D) de acordo com a temperatura. Experimento 2.

Tabela 3. Quociente da temperatura de respiração $\left(Q_{10}\right)$ de frutos de cultivares de maçã Gala e Fuji; quiuí Hayward e Bruno; caqui Fuyu e Rama Forte e pêssego Jubileu. Experimento 2.

\begin{tabular}{|c|c|c|c|c|c|c|c|c|}
\hline \multirow[t]{2}{*}{ Temperatura $\left({ }^{\circ} \mathrm{C}\right)$} & \multicolumn{2}{|c|}{ Maçã } & \multicolumn{2}{|c|}{ Quiuí } & \multicolumn{2}{|c|}{ Caqui } & Pêssego & \multirow[t]{2}{*}{ Média } \\
\hline & Gala & Fuji & Bruno & Hayward & Fuyu & Rama-Forte & Eldorado & \\
\hline 0 & 1,0 & 1,0 & 1,0 & 1,0 & 1,0 & 1,0 & 1,0 & 1,0 \\
\hline 10 & 6,9 & 4,3 & 4,5 & 4,9 & 8,6 & 8,4 & 7,4 & 6,4 \\
\hline 20 & 4,5 & 3,7 & 3,8 & 4,2 & 4,5 & 5,5 & 5,4 & 4,5 \\
\hline
\end{tabular}


causa incremento de duas a quatro vezes na taxa respiratória de frutos, o que não está de acordo com os resultados obtidos neste trabalho. $\mathrm{O}$ incremento na taxa respiratória pelo aumento da temperatura, medido pelo valor $\mathrm{Q}_{10}$, variou de acordo com a espécie e com a faixa de temperatura, e atingiu valores superiores a 4 (Tabela 3). A $10^{\circ} \mathrm{C}$, o valor $\mathrm{Q}_{10}$ apresentou os valores de 4,3, na maçã 'Fuji', e de 8,6, no caqui 'Fuyu', e, em média, o valor ficou em 6,4 . No entanto, a $20^{\circ} \mathrm{C}$, o $\mathrm{Q}_{10}$ não foi tão elevado, apresentando valores de 3,7 , na maçã 'Fuji', 5,5, no caqui 'Rama Forte', e 4,5 em média. Segundo Kader (1987), o valor $Q_{10}$ possui variações de acordo com as temperaturas consideradas no cálculo, concordando com os resultados obtidos neste trabalho.

Existem diferenças entre as espécies estudadas e entre as condições de armazenamento. Chitarra (1998) e Manolopoulou \& Papadopoulou (1998) afirmam que a intensidade da taxa respiratória está inversamente relacionada com o potencial de armazenamento da fruta. No entanto, considerando os resultados obtidos neste trabalho, observou-se que esta afirmação é verdadeira para comparar cultivares de uma mesma espécie (Tabela 1), em que cultivares que apresentam uma curta vida pós-colheita apresentaram maior taxa respiratória, como o caqui 'Taubaté', o pêssego 'Maciel' e o quiuí 'Bruno', do que as com maior potencial de armazenamento e menor respiração, como o caqui 'Fuyu', o pêssego 'Eldorado' e o quiuí 'Hayward'. Na comparação entre espécies, esta regra não é válida, pois o quiuí 'Bruno' apresentou atividade respiratória maior que o pêssego 'Jubileu' e o caqui 'Fuyu', os quais apresentam menor potencial de armazenamento que o quiuí 'Bruno'.

Quanto à condição de armazenamento, observou-se que o uso do armazenamento com modificação da atmosfera causou redução na taxa respiratória, que variou entre $12,1 \%$, no caqui 'Fuyu', e $16 \%$, na maçã 'Gala', com média de redução de 14,3\% (Tabela 4). Este resultado está de acordo com Fonseca et al. (2002), que afirmam que o baixo $\mathrm{O}_{2}$ ou o alto $\mathrm{CO}_{2}$ reduzem a atividade respiratória dos frutos. De acordo com Kader (1986), a redução na atividade respiratória pelo baixo $\mathrm{O}_{2}$ é decorrente do decréscimo na atividade de várias enzimas com atividade oxidase, como a citocromo oxidase, polifenoloxidase, ácido ascórbico oxidase e ácido glicólico oxidase. Quanto ao efeito do $\mathrm{CO}_{2}$ sobre a respiração, algumas hipóteses têm sido formuladas: ele pode reduzir a produção de $\mathrm{CO}_{2}$ diretamente, inibindo a rota glicolítica, agindo na fosfofrutoquinase, e o ciclo dos ácidos tricarboxílicos, agindo na succinato oxidase e na isocitrato desidrogenase, e indiretamente, reduzindo a ação do etileno sobre enzimas envolvidas no processo respiratório (Mathooko, 1996; Fonseca et al., 2002; Liu et al., 2004).

Em relação ao estádio de maturação, observou-se que, na maioria das situações, não houve efeito deste fator sobre a taxa respiratória (Tabela 1). No entanto, para as cultivares de maçã estudadas e para o caqui 'Giombo', armazenados a $0^{\circ} \mathrm{C}$, observou-se, respectivamente, uma taxa respiratória de 17 e $13 \%$ maior no estádio de maturação maduro, quando comparado ao estádio de maturação verde-maduro. Isso evidencia que estádio de maturação, se possível, deve

Tabela 4. Efeito da modificação da atmosfera na redução da taxa respiratória $\left(\mathrm{mL}\right.$ de $\left.\mathrm{CO}_{2} \mathrm{~kg}^{-1} \mathrm{~h}^{-1}\right)$ em frutas armazenadas a $0^{\circ} \mathrm{C}$. Experimento $3^{(1)}$.

\begin{tabular}{|c|c|c|c|c|}
\hline \multirow[t]{2}{*}{ Espécie $^{(2)}$} & \multicolumn{2}{|c|}{ Condição de armazenamento } & \multirow[t]{2}{*}{ Média } & \multirow{2}{*}{$\begin{array}{c}\text { Redução da taxa respiratória } \\
\text { pela atmosfera modificada }(\%)\end{array}$} \\
\hline & Armazenamento refrigerado & Atmosfera modificada & & \\
\hline Pêssego Jubileu & 1,32 & 1,14 & $1,23 b$ & 13,6 \\
\hline Caqui Fuyu & 0,58 & 0,51 & $0,54 \mathrm{c}$ & 12,1 \\
\hline Quiuí Bruno & 1,43 & 1,21 & $1,32 \mathrm{a}$ & 15,4 \\
\hline Maçã Gala & 0,50 & 0,42 & $0,46 \mathrm{~d}$ & 16,0 \\
\hline Média & $0,96 \mathrm{~A}$ & $0,82 \mathrm{~B}$ & & 14,3 \\
\hline $\mathrm{CV}(\%)$ & & & & 7,17 \\
\hline
\end{tabular}

${ }^{(1)}$ Médias seguidas por letras distintas, maiúsculas na linha e minúsculas na coluna, diferem entre si pelo teste de Duncan, a $5 \%$ de probabilidade. (2)Pêssego 'Jubileu', quiuí 'Bruno' e maçã 'Gala': $5 \mathrm{kPa}$ de $\mathrm{O}_{2}+5 \mathrm{kPa}$ de $\mathrm{CO}_{2}$; Caqui 'Fuyu': $10 \mathrm{kPa}$ de $\mathrm{O}_{2}+10 \mathrm{kPa}$ de $\mathrm{CO}_{2}$. 
ser considerado na previsão da taxa respiratória dos frutos, pois pode apresentar um efeito maior que a modificação da atmosfera.

\section{Conclusões}

1. As cultivares de maçã Gala, a $0^{\circ} \mathrm{C}$, e Fuji, a 0 e $10^{\circ} \mathrm{C}$, não apresentam pico respiratório característico de frutos climatéricos.

2. A cultivar, a temperatura de armazenamento e a modificação da atmosfera influenciam a taxa respiratória.

3. Existe relação entre menor potencial de armazenamento e maior taxa respiratória quando se considera um grupo de cultivares de mesma espécie, mas não quando se comparam diferentes espécies de frutas.

4. O valor $\mathrm{Q}_{10}$ é variável em função da temperatura e da espécie.

\section{Referências}

BRACKMANN, A.; CHITARRA, A.B. Atmosfera controlada e atmosfera modificada. In: BOREN, F.M. (Ed.). Armazenamento e processamento de produtos agrícolas. Lavras: Ufla/SBEA, 1998. p.133-170.

BRACKMANN, A.; GIEHL, R.F.H.; SESTARI, I.; STEFFENS, C.A. Armazenamento de nêsperas (Eriobotryia japonica, Lindl.) cv. Mizuho em atmosfera modificada. Revista Científica Rural, v.9, p.18-24, 2004.

BRACKMANN, A.; STREIF, J. Ethylene, $\mathrm{CO}_{2}$ and aroma volatiles production by apple cultivars. Acta Horticulturae, v.368, p.51-58, 1994.

BRACKMANN, A.; WACLAWOVSKY, A.J.; DONAZZOLO, J. Resposta da maçã cv. Fuji ao etileno no armazenamento em atmosfera controlada. Ciência Rural, v.31, p.953-956, 2001.

CHEN, X.; HERTOG, M.L.A.T.M.; BANKS, N.H. The effect of temperature on gas relations in MA packages for capsicums (Capsicum annuum L., cv. Tasty): an integrated approach. Postharvest Biology and Technology, v.20, p.71-80, 2000.

CHITARRA, M.I.F. Fisiologia e qualidade de produtos vegetais. In: BOREN, F.M. (Ed.). Armazenamento e processamento de produtos agrícolas. Lavras: Ufla/SBEA, 1998. p.1-57.
FONSECA, S.C.; OLIVEIRA, F.A.R.; BRECHT, J.K. Modelling respiration rate of fresh fruits and vegetables for modified atmosphere packages: a review. Journal of Food Engineering, v.52, p.99-119, 2002.

KADER, A.A. Biochemical and physiological basis for effects of controlled and modified atmospheres on fruits and vegetables. Food Technology, v.40, p.99-104, 1986.

KADER, A.A. Respiration and gas exchange of vegetables. In: WEICHMANN, J. (Ed.). Postharvest Physiology of Vegetables. New York: M. Dekker, 1987. p.25-43.

LIU, S.; YANG, Y.; MURAYAMA, H.; TAIRA, S.; FUKUSHIMA, T. Effects of $\mathrm{CO}_{2}$ on respiratory metabolism in ripening banana fruit. Postharvest Biology and Technology, v.33, p.27-34, 2004.

MAHAJAN, P.V.; GOSWANI, T.K. Enzyme kinetics based modeling of respiration rate of apple. Journal of Agricultural Engineering Research, v.79, p.399-406, 2001.

MANOLOPOULOU, H.; PAPADOPOULOU, P. A study of respiratory and physico-chemical changes of four kiwi fruit cultivars during cool-storage. Food Chemistry, v.63, p.529-534, 1998.

MATHOOKO, F.M. Regulation of respiratory metabolism in fruits and vegetables by carbon dioxide. Postharvest Biology and Technology, v.9, p.247-264, 1996.

PEPPELENBOS, H.W.; TIJSKENS, L.M.M.; VAN'T LEVEN, J.; WILKINSON, E.C. Modelling oxidative and fermentative carbon dioxide production of fruits and vegetables. Postharvest Biology and Technology, v.9, p.283-295, 1996.

PETRACEK, P.D.; JOLES, D.W.; SHIRAZI, A.; CAMERON, A.C. Modified atmosphere packaging of sweet cherry (Prunus avium L., cv. 'Sams') fruit: metabolic responses to oxygen, carbon dioxide, and temperature. Postharvest Biology and Technology, v.24, p.259-270, 2002.

SAQUET, A.A.; STREIF, J. Investigations on the respiration and the ethylene production of some new apple cultivars. ErwerbsObstbau, v.42, p.109-112, 2000.

SAQUET, A.A.; STREIF, J. Respiração e produção de etileno de maçãs armazenadas em diversas concentrações de oxigênio. Revista Brasileira de Agrociência, v.8, p.71-75, 2002.

SONG, Y.; VORSA, N.; YAM, K.L. Modeling respirationtranspiration in a modified atmosphere packaging system containing blueberry. Journal of Food Engineering, v.53, p.103-109, 2002.

STEFFENS, C.A. Maturação e qualidade pós-colheita de maçãs, 'Gala' e 'Fuji', com aplicação pré-colheita de aminoetoxivinilglicina e ethephon. 2003. 88p. Dissertação (Mestrado) - Universidade Federal de Santa Maria, Santa Maria. 